\title{
Jcrpe-2018-0193.R1
}

Original Article

DOI: $10.4274 /$ jcrpe.0193

\section{Diazoxide Causality Assessment of a Pericardial Effusion in a Child with Kabuki Syndrome}

\section{Maffre I et al. Pericardial Effusion Under Diazoxide}

Irene Maffre ${ }^{1,3}$; Marie Vincenti, $\mathrm{MD}^{1,4}$; Fabienne Dalla Vale, $\mathrm{MD}^{2}$; Cyril Amouroux, $\mathrm{MD}^{2}$; Oscar Werner, MD ${ }^{1}$; Alexandra Meilhac ${ }^{1}$; Gaelle de Barry, PharmD ${ }^{3}$, Pascal Amedro, MD, $\mathrm{PhD}^{1,4}$

${ }^{1}$ Pediatric and Congenital Cardiology Department, M3C Regional Centre, University Hospital, Montpellier, France ${ }^{2}$ Pediatric and Endocrinology Nephrology Department, M3C Regional Centre, University Hospital, Montpellier, France

${ }^{3}$ Hospital Pharmacy Department, University Hospital, Montpellier, France ${ }^{4}$ PhyMedExp, CNRS, INSERM, University of Montpellier, Montpellier, France

Address for Correspondence: Dr. Pascal Amedro, Paediatric and Congenital Cardiology Department, CHU Arnaud De Villeneuve, 371 avenue du Doyen Gaston Giraud, 34295 Montpellier Cedex 5, France,

p-amedro@chu-montpellier.fr,

Tel +33467336639,

Fax +33437332129

Conflict of interest: None declared

Received: 27.08.2018

Accepted: 23.10 .2018

ORCID ID: Irene Maffre: 0000-0001-6553-6074; Marie Vincenti: 0000-0002-8201-5024; 
Fabienne Dalla Vale: 0000-0002-8165-1010; Cyril Amouroux: 0000-0003-4251-6825; Oscar Werner: 0000-0002-3741-0498; Alexandra Meihlac: 0000-0003-1892-2014; Gaelle de Barry: 0000-0002-8221-4787; Pascal Amedro: 0000-0003-3649-0294

Key words: Pericardial effusion, Diazoxide, Kabuki syndrome, paediatrics.

Competing interests: None.

Funding: This research did not receive any specific grant from any funding agency in the public, commercial or not-for-profit sector.

Patient consent: Informed consent has been obtained from the patient's parent for publication of the case report.

\section{Dear editor,}

We report a new adverse event of diazoxide, e.g. a severe pericardial effusion, in a 15-monthold girl with Kabuki syndrome. We performed, for the first time, a causality assessment of this drug toxicity and found a high probability of a causal relationship between diazoxide and pericardial effusion. Indeed, after the treatment was suspended, the pericardial effusion regressed and reappeared when diazoxide was reintroduced again. Using the Naranjo algorithm, the adverse drug reaction probability scale total score was rated at 10 (e.g. the reaction is considered definite if the score is 9 or higher) (1).

Kabuki syndrome (KS) is a rare multiple congenital malformation syndrome, in which congenital heart defects have been described. However, pericardial effusion is not a common complication. A 15 month-old girl with KS (KDM6A mutation) was referred to our tertiary care paediatric cardiology centre for respiratory and hemodynamic distress. Her medical history involved congenital hypothyroidism treated from birth by levothyroxine, congenital hyperinsulinism, and renal malformation. She had been treated by diazoxide for 10 months 
(dose of $10 \mathrm{mg} / \mathrm{kg} / \mathrm{d}$ ), with a $5 \%$ maltose dextrin diet, under correct glycaemic monitoring. Pediatric cardiologist confirmed by echocardiography the absence of any CHD or pulmonary hypertension $(\mathrm{PH})$, but diagnosed a severe 25-diameter pericardial effusion. Ibuprofen and colchicine were started, successively, but had not effect. On day 12, a pericardial puncture was performed. The usual etiological assessment for pericarditis was negative (brain natriuretic peptide, troponin, thyroid status, and common viruses). On day 16 , the diazoxide was suspended and a continuous diet with $10 \%$ maltose dextrin was introduced. The pericardial effusion started to regress at day 25 and disappeared at day 28. At day 29, in the absence of alternative therapeutic and in order to preserve the patient pancreatic function, diazoxide was reintroduced at low dose $(3 \mathrm{mg} / \mathrm{kg} / \mathrm{d})$ under close echocardiographic monitoring. On day 34 (5 days after diazoxide was reintroduced), a 3-mm pericardial effusion was diagnosed. The diazoxide was then increased to $4.5 \mathrm{mg} / \mathrm{kg} / \mathrm{d}$ and food intake was decreased to $5 \%$ maltose dextrin. At day 36 , the pericardial effusion remained stable $(3 \mathrm{~mm})$. However, at day 47, e.g. 19 days after reintroduction of diazoxide, pericardial effusion significantly increased to $6 \mathrm{~mm}$. Therefore, diazoxide was definitively stopped. At day 52, e.g. 5 days after diazoxide was definitively stopped, the echocardiography showed a regression of the pericardial effusion. Currently, after a 6-month follow-up since diazoxide was suspended, the patient is under good condition with normal echocardiography assessments.

Two cases of potential toxicity of diazoxide with pericardial effusion have been previously reported $(2,3)$. A recent retrospective study on 295 children with congenital hyperinsulinism reported that $2.4 \%$ were diagnosed with $\mathrm{PH}$ after diazoxide initiation (4). Classically, pericardial effusion may occur in severe $\mathrm{PH}$, however, our patients did not present with $\mathrm{PH}$. Another drug with a similar action, the minoxidil, was suspected to be associated with pericardial effusion, that may be explain the cardiac toxicity of the drug (5). Therefore, we 
recommend monitoring patient with KS under diazoxide with echocardiography to detect any pericardial effusion.

\section{References}

1. Naranjo CA, Busto U, Sellers EM, Sandor P, Ruiz I, Roberts EA, et al. A method for estimating the probability of adverse drug reactions. Clin Pharmacol Ther. 1981;30(2):239-45.

2. Avatapalle B, Banerjee I, Malaiya N, Padidela R. Echocardiography monitoring for diazoxide induced pericardial effusion. BMJ Case Rep. 2012;2012.

3. Silvani P, Camporesi A, Mandelli A, Wolfler A, Salvo I. A case of severe diazoxide toxicity. Paediatr Anaesth. 2004;14(7):607-9.

4. Herrera A, Vajravelu ME, Givler S, Mitteer L, Avitabile CM, Lord K, et al. Prevalence of Adverse Events in Children with Congenital Hyperinsulinism Treated with Diazoxide. J Clin Endocrinol Metab. 2018. [cited 2018 Oct 8]

5. Reichgott MJ. Minoxidil and pericardial effusion: an idiosyncratic reaction. Clin Pharmacol Ther. 1981;30(1):64-70. 